Pesq. Vet. Bras. 29(11):899-904, novembro 2009

\title{
Aspectos clínicos e patológicos em bovinos afetados por raiva com especial referência ao mapeamento do antígeno rábico por imuno-histoquímica ${ }^{1}$
}

\author{
Pedro M.O. Pedroso ${ }^{2}$, Edson M. Colodel ${ }^{3}$, Caroline A. Pescador ${ }^{3}$, Laura P. \\ Arruda $^{3}$ e David Driemeier ${ }^{*}$
}

\begin{abstract}
Pedroso P.M.O., Colodel E.M., Pescador C.A., Arruda L.P. \& Driemeier D. 2009. [Clinical and pathological aspects in cattle affected by rabies with special reference to the rabies antigen mapping by immunohistochemistry.] Aspectos clínicos e patológicos em bovinos afetados por raiva com especial referência ao mapeamento do antígeno rábico por imuno-histoquímica. Pesquisa Veterinária Brasileira 29(11):899-904. Setor de Patologia Veterinária, Faculdade de Veterinária, Universidade Federal do Rio Grande do Sul, Av. Bento Gonçalves 9090, Porto Alegre, RS 91540-000, Brazil. E-mail: davetpat@ufrgs.br

This retrospective study included clinical and pathological findings from 15 cattle affected by rabies. Thirteen of the 15 cases were confirmed by direct immunofluorescence. Cattle between 4 months and 8 years of age were affected. Clinical course ranged from 3 to 7 days. Paralytical form was the most common clinical picture and included incoordination, paresis, and paralysis of the pelvic members, besides recumbence, paddling, and death. The main histopathological findings were lymphoplasmacytic meningoencephalitis associated with characteristic Negri bodies in $86.6 \%$ of the cases. All cases showed antirabies immunostaining, which were most prominent in the brainstem including medulla oblongata, pons, and midbrain, besides trigeminal ganglion. Positive labeling was present within axons, dendrites, and perikarya of neurons as aggregates of granules or round formations associated with varying numbers of inclusion bodies. Immunostaining was also observed in the Purkinje neurons and their processes in the molecular layer, in the neurons of of the brainstem, and deep layer of the telencephalic cortex. Immunohistochemistry may be an important auxiliary tool for the diagnosis of rabies, especially in circumstances in which refrigeration cannot be adequately maintained, and in cases characterized by nonsuppurative meningoencephalitis with absence of inclusion bodies.
\end{abstract}

INDEX TERMS: Lyssavirus, rabies, immunohistochemistry, cattle diseases.

RESUMO.- Este estudo retrospectivo incluiu achados clínicos e patológicos de 15 bovinos afetados por raiva. Em treze dos quinze casos, raiva foi confirmada por imuno-

\footnotetext{
${ }^{1}$ Recebido em 18 de maio de 2009.

Aceito para publicação em 9 de julho de 2009.

Parte da Dissertação de Mestrado do primeiro autor, Programa de Pós-Graduação em Ciências Veterinárias, Universidade Federal do Rio Grande do Sul (UFRGS), Av. Bento Gonçalves 9090, Porto Alegre, RS 95320-000, Brasil.

2 Setor de Patologia Veterinária (SPV), Departamento de Patologia Clínica Veterinária, Faculdade de Veterinária, UFRGS, Porto Alegre, RS. "Autor para correspondência: davetpat@ufrgs.br

${ }^{3}$ Departamento de Clínica Médica Veterinária, Faculdade de Agronomia e Medicina Veterinária, Universidade Federal de Mato Grosso (UFMS), Av. Fernando Correia da Costa s/n, Bairro Coxipó, Cuiabá, MT 78068-900, Brasil.
}

fluorescência direta. Bovinos entre 4 meses e 8 anos foram afetados. O curso clínico variou de três a sete dias. A forma paralítica foi a mais frequente e incluiu incoordenação, paresia e paralisia dos membros pélvicos, decúbito, movimentos de pedalagem e morte. Os principais achados histopatológicos foram meningoencefalite linfoplasmocitária associada com corpúsculos de Negri em 86,6\% dos casos. Todos os casos foram positivos na imuno-histoquímica para raiva, cujas reações foram mais evidentes no tronco encefálico, incluindo bulbo, ponte e mesencéfalo, além de gânglio trigêmeo. A imuno-histoquímica demonstrou o vírus da raiva em axônios, dendritos e pericário de neurônios, como agregados de grânulos ou em formações arredondadas associadas com números variáveis de corpúsculos de inclusão virais nos neurôni- 
os. Houve também marcação nos neurônios de Purkinje e de seus processos na camada molecular, nos núcleos do tronco encefálico e camada profunda do córtex telencefálico. A imuno-histoquímica pode ser importante ferramenta diagnóstica no diagnóstico da raiva, especialmente em situações nas quais não é possível manter refrigeração adequada das amostras e em casos com meningoencefalite não-supurativa e ausência de corpúsculos de inclusão.

TERMOS DE INDEXAÇÃO: Lyssavirus, raiva, imuno-histoquímica, doenças de bovinos.

\section{INTRODUÇÃO}

A raiva é uma zoonose causada por um Lyssavirus (Radostits et al. 2002, Rodriguez et al. 2007) que ocorre em quase todo o mundo. Na América do Sul, o principal transmissor é o morcego hematófago Desmodus rotundus (Martinez-Burnes et al. 1997, Rodriguez et al. 2007) que transmite a doença pela mordida, cuja saliva contém o vírus (Summers et al. 1995). No Brasil, bovinos e equinos são as espécies mais afetadas (Peixoto et al. 2000). A raiva pode cursar com uma forma furiosa e uma paralítica. A furiosa é mais frequente em caninos e apresenta lesões no córtex cerebral, hipocampo e tálamo (Sureau et al. 1991). A paralítica é mais comum em bovinos e está associada com lesões na medula espinhal, tronco encefálico e cerebelo (Batista et al. 2007, Fernandes \& RietCorrea 2007). Os principais sinais clínicos em bovinos incluem incoordenação (Radostits et al. 2002, Langohr et al. 2003, Reis et al. 2003, Lima et al. 2005), paresia dos membros pélvicos (Rondon et al. 1995, Riet-Correa et al. 2002, Barros et al. 2006) e torácicos (Lima et al. 2005), decúbito esternal ou lateral e morte (Langohr et al. 2003, Lima et al. 2005, Rech 2007).

As lesões de raiva são geralmente limitadas ao sistema nervoso central (SNC) (Jubb \& Huxtable 1993). Não há lesões macroscópicas significativas (Fernandes \& RietCorrea 2007). Os achados histopatológicos mais importantes incluem meningoencefalite e meningomielite linfoplasmocitária (Perl \& Good 1991, Fernandes \& Riet-Correa 2007) associadas com ganglioneurite nos gânglios e nervos cranianos e espinhais (Jubb \& Huxtable 1993, Swanepoel 2004, Rech et al. 2006). A confirmação do diagnóstico pode ser feita pela observação de corpúsculos de inclusão intracitoplasmáticos (corpúsculo de Negri) no exame histopatológico (Callan \& Van Metre 2004) ou por imunofluorescência direta (IFD) e inoculação intracerebral em camundongos. Devido sua rapidez (horas) e acurácia (sensibilidade e especificidade próximas a $100 \%$ ), a IFD é o teste padrão utilizado para o diagnóstico da raiva (Zimmer et al. 1990, Rodriguez et al. 2007, Teixeira et al. 2008). A inoculação intracerebral em camundongos é prova diagnóstica complementar com alta sensibilidade, mas demorada, se comparada à IFD (Germano et al. 1977). A imuno-histoquímica (IHQ) é de fácil utilização em amostras fixadas em formol, diminuindo o risco de alterações autolíticas comprometerem o diagnóstico (Radostits et al. 2002, Arslan et al. 2004, Pedroso et al. 2008). Além disso, tem sido empregada em estudos de patogenia e diagnóstico da doença em humanos e animais (Jackson \& Reimer 1989, Hamir et al. 1992, Hamir et al. 1996, López et al. 1998/2001, Woldehiwet 2005). Este estudo retrospectivo identificou as regiões do sistema nervoso em que houve marcação imuno-histoquímica do antígeno da raiva, além de descrever outros aspectos clínicos e patológicos observados em 15 casos naturais de raiva bovina provenientes das Regiões Sul e CentroOeste do país.

\section{MATERIAL E MÉTODOS}

Este estudo incluiu dados de 15 casos de bovinos naturalmente infectados com vírus da raiva e mortos pela doença. Oito casos foram provenientes do Laboratório de Patologia Veterinária da Universidade Federal de Mato Grosso (LPV-UFMT) e os demais sete, do Setor de Patologia Veterinária da Universidade Federal do Rio Grande do Sul (SPV-UFRGS). Após corte longitudinal, metade do encéfalo de cada animal foi fixado (entre 24 horas e uma semana) em formol $10 \%$ e submetido a 12 cortes transversais (adaptado de Rech 2007). Os cortes transversais analisados neste estudo foram medula espinhal cervical (MC), bulbo na altura do óbex (BO), ponte na altura dos pedúnculos cerebelares (PO), mesencéfalo na altura dos colículos rostrais (ME), tálamo (TA), cerebelo (CE), córtex frontal (CF), córtex parietal (CP), córtex temporal (CT), córtex occipital (CO), e hipocampo (HC). O gânglio trigêmeo (GT) foi testado em sete casos. Os cortes foram processados de forma rotineira para histologia, cortados a $5 \mu \mathrm{m}$ de espessura e corados pela hematoxilina e eosina ( $\mathrm{HE})$. Cortes histológicos de cada uma dessas regiões foram submetidos à técnica de IHQ para raiva, conforme descrição anterior (Pedroso et al. 2008). Utilizou-se recuperação antigênica com calor e solução de tampão citrato $10 \mathrm{mM}(\mathrm{pH} \mathrm{6,0)}$ e anticorpo primário policlonal (anti-rabies polyclonal Chemicon \#5199, adaptado de Rech 2007) na diluição de 1:1000 em PBS (phosphate buffered saline), durante 60 minutos em estufa a $37^{\circ} \mathrm{C}$. Para revelação, empregou-se cromógeno vermelho (Vector Laboratories ${ }^{\circledR}$, NovaRED, 94010 , Ingold Road 30, Burlingame, CA, EUA) por 5 minutos ou até o corte ficar vermelho-tijolo. Subsequentemente, as lâminas foram contra-coradas com hematoxilina de Harris por 1 minuto, avaliadas em microscópio óptico quanto à intensidade e distribuição das marcações. Às diferentes intensidades de marcação foram atribuídos os graus de 0 (ausente), 1 (leve), 2 (moderado) e 3 (acentuado). Amostras de SNC de um caso de raiva bovina confirmado por IFD, inoculação intracerebral em camundongo e IHQ serviram como controle positivo. Todas as amostras utilizadas foram negativas para herpesvírus bovino tipo 5 pela técnica de reação em cadeia de polimerase (PCR).

\section{RESULTADOS}

Apenas dois, dos 15 casos estudados não foram testados por IFD. Todos os testados foram positivos. Bovinos com idade de 4 meses a 8 anos foram afetados; a idade média foi 3 anos e 7 meses. Os casos provenientes de Mato Grosso eram da raça Nelore (5/8) ou sem indicação de raça $(3 / 8)$ e os do Rio Grande do Sul eram mestiços (3/7), Jersey (1/7), Holandês (1/7), Caracu (1/7) e um caso 
sem informação de raça. O curso clínico variou de três a sete dias. A forma paralítica foi a manifestação clínica observada e se caracterizou por incoordenação motora (9/15), movimentos de pedalagem (9/15), paresia e paralisia dos membros pélvicos (8/15), decúbito lateral (8/15) e esternal (7/15), opistótono (5/15) e morte (15/15). Relatou-se também sialorréia (7/15), agressividade (3/15) e nistagmo (1/15).

Os principais achados histopatológicos foram meningoencefalite e ganglionite com manguitos perivasculares compostos por linfócitos e plasmócitos, neuronofagia e gliose.
Cromatólise central e vacuolização em neurônios também foi observada em cinco casos no gânglio trigêmeo. Corpúsculos de inclusão intracitoplasmáticos eosinofílicos (corpúsculos de Negri) foram observados em 86,6\% (13/15) dos casos, principalmente nos neurônios do gânglio trigêmeo (6/7) e neurônios de Purkinje do cerebelo (10/15).

Os resultados observados à imuno-histoquímica dos cortes seriados do sistema nervoso central estão apresentados no Quadro 1. Houve marcação do antígeno rábico em todos os cortes de bulbo na altura do óbex, ponte, mesencéfalo na altura dos colículos rostrais e
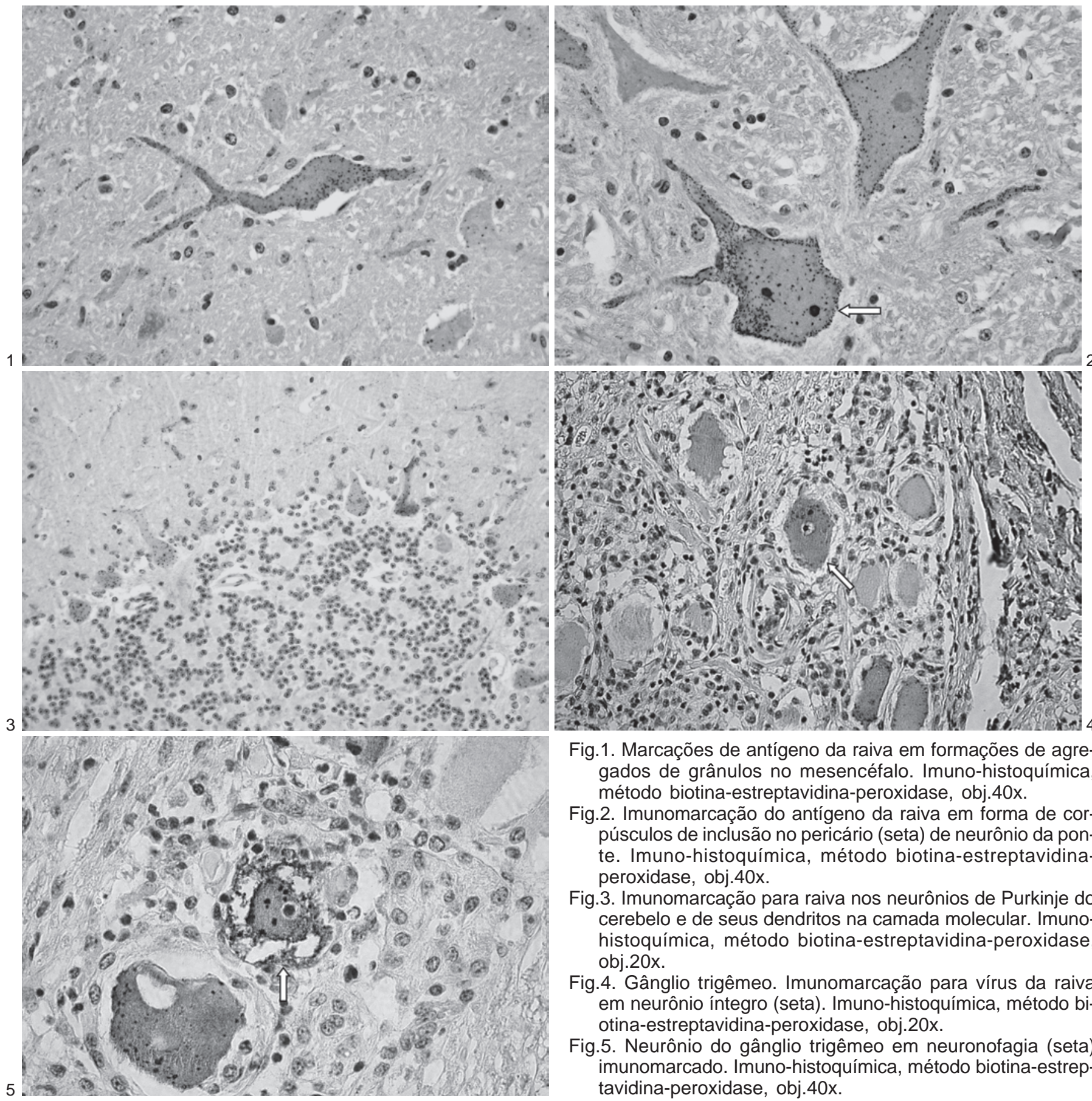

Fig.1. Marcações de antígeno da raiva em formações de agregados de grânulos no mesencéfalo. Imuno-histoquímica, método biotina-estreptavidina-peroxidase, obj.40x.

Fig.2. Imunomarcação do antígeno da raiva em forma de corpúsculos de inclusão no pericário (seta) de neurônio da ponte. Imuno-histoquímica, método biotina-estreptavidinaperoxidase, obj.40x.

Fig.3. Imunomarcação para raiva nos neurônios de Purkinje do cerebelo e de seus dendritos na camada molecular. Imunohistoquímica, método biotina-estreptavidina-peroxidase, obj.20x.

Fig.4. Gânglio trigêmeo. Imunomarcação para vírus da raiva em neurônio íntegro (seta). Imuno-histoquímica, método biotina-estreptavidina-peroxidase, obj.20x.

Fig.5. Neurônio do gânglio trigêmeo em neuronofagia (seta) imunomarcado. Imuno-histoquímica, método biotina-estreptavidina-peroxidase, obj.40x. 
Quadro 1. Locais e intensidade de marcações imuno-histoquímicas em cortes histológicos de SNC de bovinos naturalmente afetados por raiva

\begin{tabular}{ccccccccccccc}
\hline $\begin{array}{c}\text { Bovino } \\
\mathrm{n}^{\circ}\end{array}$ & $\mathrm{MC}^{\mathrm{a}}$ & $\mathrm{BO}^{\mathrm{b}}$ & $\mathrm{PO}^{\mathrm{c}}$ & $\mathrm{ME}^{\mathrm{d}}$ & $\mathrm{TA}^{\mathrm{e}}$ & $\mathrm{CE}^{\mathrm{f}}$ & $\mathrm{CF}^{\mathrm{g}}$ & $\mathrm{CP}^{\mathrm{h}}$ & $\mathrm{CT}^{\mathrm{i}}$ & $\mathrm{CO}^{\mathrm{j}}$ & $\mathrm{HC}^{\mathrm{k}}$ & $\mathrm{GT}^{\mathrm{l}}$ \\
\hline 1 & $1^{\mathrm{m}}$ & 1 & $2^{\mathrm{n}}$ & 2 & $0^{\circ}$ & 1 & 0 & 1 & 0 & 0 & 0 & 1 \\
2 & 0 & $3^{\mathrm{p}}$ & 3 & 3 & 3 & 0 & 0 & 3 & 0 & 2 & 1 & 1 \\
3 & 2 & 3 & 3 & 2 & 3 & 0 & 1 & 0 & 0 & 3 & 2 & $\mathrm{NA}$ \\
4 & $\mathrm{NA}$ & $\mathrm{NA}$ & 3 & 3 & 3 & 3 & 2 & 1 & 2 & 1 & 2 & $\mathrm{NA}$ \\
5 & $\mathrm{NA}$ & 3 & 3 & 3 & 3 & 3 & 3 & 3 & 3 & 3 & 3 & 3 \\
6 & 2 & 3 & 1 & 2 & 0 & 3 & 3 & 3 & 3 & 3 & 3 & $\mathrm{NA}$ \\
7 & 2 & 1 & 3 & 2 & 2 & 2 & 1 & 3 & 3 & 2 & 1 & $\mathrm{NA}$ \\
8 & $\mathrm{NA}$ & 3 & 3 & 2 & 3 & 1 & 3 & 3 & 2 & 0 & 0 & $\mathrm{NA}$ \\
9 & $\mathrm{NA}$ & 1 & 1 & 1 & 2 & 3 & 3 & 0 & 0 & 0 & 0 & $\mathrm{NA}$ \\
10 & $\mathrm{NA}$ & 3 & 2 & 2 & 1 & 1 & 1 & $\mathrm{NA}$ & $\mathrm{NA}$ & 0 & $\mathrm{NA}$ & 3 \\
11 & $\mathrm{NA}$ & 2 & 3 & 3 & 3 & 2 & 3 & 3 & 3 & 2 & 1 & $\mathrm{NA}$ \\
12 & 1 & $\mathrm{NA}$ & 1 & 1 & 2 & 1 & 1 & 1 & 1 & 1 & 1 & $\mathrm{NA}$ \\
13 & 2 & 2 & 3 & 2 & 2 & 2 & 3 & 3 & 2 & 3 & 2 & 1 \\
14 & 1 & 3 & 3 & 3 & 0 & 1 & 2 & 3 & 3 & 3 & 3 & 3 \\
15 & 1 & 3 & 3 & 3 & 1 & 3 & 1 & 2 & 1 & 1 & 2 & 2 \\
$\mathrm{IM}$ & 1,33 & 2,38 & 2,46 & 2,26 & 1,86 & 1,73 & 1,8 & 2,07 & 1,64 & 1,6 & 1,5 & 2
\end{tabular}

amedula espinhal cervical, bbulbo na altura do óbex, ${ }^{\mathrm{C}}$ ponte com pedúnculos cerebelares, ${ }^{\mathrm{d}}$ mesencéfalo na altura dos colículos rostrais, etálamo, ${ }^{\mathrm{f}}$ cerebelo, ${ }^{\mathrm{g}}$ córtex frontal, ${ }^{\mathrm{h}}$ córtex parietal, ${ }^{\mathrm{i}}$ córtex temporal, j'órtex occipital, khipocampo, 'gânglio trigêmeo, ${ }^{m}$ marcação leve, ${ }^{n}$ marcação moderada, ${ }^{\circ}$ ausência de marcação, Pmarcação acentuada, NA: secção do SNC não avaliada, IM: intensidade média de marcação imuno-histoquímica por região do SNC.

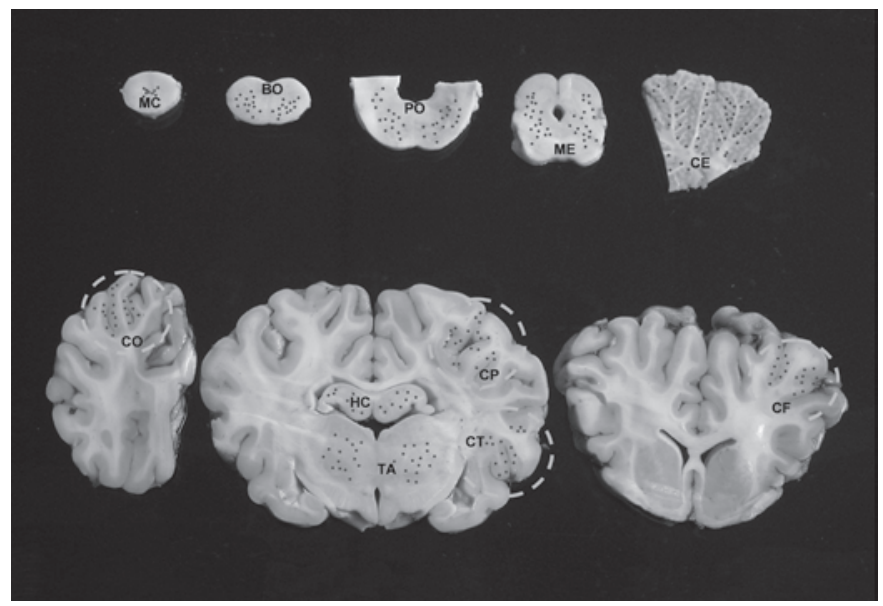

Fig.6. Cortes seriados empregados no estudo histológico e imunohistoquímico de bovinos com raiva: medula espinhal cervical (MC), secção do bulbo na altura do óbex (BO), ponte com pedúnculos cerebelares $(\mathrm{PO})$, mesencéfalo na altura dos colículos rostrais (ME), tálamo (TA), cerebelo (CE), córtex frontal (CF), córtex parietal (CP), córtex temporal (CT), córtex occipital (CO) e hipocampo (HC). Os pontos vermelhos representam os locais de marcação imuno-histoquímica.

gânglio trigêmeo. Outras áreas consistentemente marcadas incluíram medula espinhal cervical $(88,88 \%)$, cerebelo e córtex frontal $(86,66 \%)$, córtex parietal $(85,71 \%)$, tálamo (80\%) e hipocampo (78,57\%). A IHQ demonstrou o vírus da raiva no pericário, axônio e dendritos de neurônios, como agregados de grânulos (Fig.1) ou em formações redondas ou ovais (Fig.2) associadas com números variáveis de corpúsculos de inclusão virais nos neurônios. No cerebelo, houve marcação nos neurônios de Purkinje e de seus processos na camada molecular (Fig.3), nos núcleos do tronco encefálico e camada profunda do córtex telencefálico. No gânglio trigêmeo, observou-se marcação em neurônios íntegros (Fig.4) e com neuronofagia (Fig.5). As regiões de marcação IHQ nos cortes seriados do sistema nervoso estão representadas na Figura 6.

\section{DISCUSSÃO}

O diagnóstico de raiva nesses casos foi baseado nas lesões histopatológicas e nos resultados de IFD (13 casos) e imuno-histoquímica. As alterações histopatológicas aqui observadas e caracterizadas por meningoencefalomielite linfoplasmocitária e ganglionite com corpúsculos de inclusão viral foram semelhantes às descritas anteriormente (Herzog 1965, Jubb \& Huxtable 1993, Langohr et al. 2003, Rech et al. 2006). Inclusões em neurônios são, na maioria das vezes, características de doenças virais. Apesar de característicos na raiva, os corpúsculos de Negri podem não ser visualizados em até $30 \%$ dos casos da doença levando-se em consideração as várias espécies afetadas (Perl \& Good 1991, Jubb \& Huxtable 1993, Rech 2007). Corpúsculos de inclusão viral foram encontrados em $86,6 \%$ dos casos, principalmente no pericário dos neurônios, tanto dos normais, quanto dos degenerados e necróticos, mas também nos axônios e dendritos. Em bovinos, os corpúsculos de Negri são frequentemente observados nos neurônios de Purkinje (Summers et al. 1995), Os principais locais com corpúsculos de Negri neste estudo foram o gânglio trigêmeo $(85,7 \%)$ e neurônios de Purkinje do cerebelo $(66,6 \%)$. Esses dois resultados confirmam os estudos anteriores que mencionam a maior frequência de corpúsculos de inclusão nos neurônios de Purkinje do cerebelo (Langohr et al. 2003, Lima et al. 2005) e no gânglio trigêmeo (Rech et al. 2006).

Corpúsculos de inclusão viral (os maiores e arredondados) foram mais facilmente observados à imuno-histo- 
química que à coloração $\mathrm{HE}$. A demonstração do antígeno viral pela IHQ tem sido associada com aumento da chance de diagnóstico da doença (Vural et al. 2001). A principal forma de marcação do vírus da raiva no estudo IHQ se caracterizou por agregados de grânulos pequenos distribuídos no citoplasma de neurônios. As regiões do SNC de bovinos afetados naturalmente por raiva que demonstraram marcação do antígeno da raiva mais evidente foram, em ordem decrescente, ponte, bulbo, mesencéfalo, córtex parietal e gânglio trigêmeo. Neste estudo, o gânglio trigêmeo foi uma importante área de detecção do antígeno rábico na IHQ, porém não tem sido utilizado na prova de IFD. A expressiva marcação viral nesses locais pode ser explicada pela propagação axonal centrípeta do vírus da raiva até o SNC (Swanepoel 2004), onde os vírus que seguem via neurônios motores chegam aos cornos ventrais da medula espinhal e núcleos motores do tronco encefálico (Fernandes \& Riet-Correa 2007).

Todos os bovinos deste estudo tiveram marcação IHQ de antígeno do vírus da raiva, incluindo as amostras fixadas em formol de dois casos que não foram submetidos à IFD. Tal situação pode ocorrer quando não é possível manter refrigeração adequada das amostras de tecidos por tempo prolongado, principalmente em regiões do país onde há deficiências de transporte e estradas e/ou se localizam a longas distâncias de centros de diagnóstico veterinário, uma vez que o procedimento padrão para o diagnóstico da raiva exige a utilização de material fresco refrigerado. A IHQ tem sido empregada para o diagnóstico de muitas infecções virais (Jogai et al. 2000) e para a visualização de quantidade, distribuição e localização celular de epítopos em cortes histológicos (Haines \& West 2005). Possibilidades diagnósticas para raiva têm sido registradas como da ordem de $87-98 \%$ pela IHQ e 87 $100 \%$ pela IFD (Zimmer et al. 1990, Vural et al. 2001). Outra aplicação importante para a IHQ no diagnóstico da raiva inclui casos de meningoencefalite não-supurativa nos quais corpúsculos de inclusão não são observados. Este estudo enfatiza a importância da IHQ na demonstração do antígeno da raiva em cortes histológicos de sistema nervoso central de bovinos afetados pela doença, especialmente nos casos que não puderam ser submetidos à imunofluorescência direta ou inoculação intracerebral em camundongos, além de contribuir no diagnóstico quando os resultados de IFD e inoculação intracerebral em camundongos são negativos. A marcação viral consistente do antígeno da raiva no tronco encefálico de 15 casos naturais de raiva bovina também permite concluir que esta área do encéfalo deve ser a área de escolha para futura seleção de cortes para imuno-histoquímica.

Agradecimentos.- Ao Instituto de Pesquisas Veterinárias Desidério Finamor (IPVDF) e ao Laboratório de Apoio à Saúde Animal do Instituto de Defesa Agropecuária do Estado de Mato Grosso (LASA-INDEA MT) pelos resultados de IFD de raiva dos materiais encaminhados. À Coordenação de Aperfeiçoamento de Pessoal de Nível Superior (CAPES) pelo suporte financeiro. Às técnicas de laboratório Ângela B. de Souza e Marília O. Belmonte pela confecção do material de estudo.

\section{REFERÊNCIAS}

Arslan A., Saglam Y.S. \& Temur A. 2004. Detection of rabies viral antigens in non-autolysed and autolysed tissues by using an immunoperoxidase technique. Vet. Rec. 155:550-552.

Barros C.S.L., Driemeier D., Dutra I.S. \& Lemos R.A.A. 2006. Doenças do sistema nervoso de bovinos no Brasil. Vallée, São Paulo, p.21-28.

Batista H.B.C.R., Franco A.C. \& Roehe P.M. 2007. Raiva: uma breve revisão. Acta Scientiae Vet. 35:125-144.

Callan R.J. \& Van Metre D.C. 2004. Viral diseases of the ruminant nervous system. Vet. Clin. North Am. Food Anim. Pract. 20:327-362.

Fernandes C.G. \& Riet-Correa F. 2007. Raiva, p.184-198. In: Riet-Correa F., Schild A.L., Lemos R.A.A. \& Borges J.R.J. (Eds), Doenças de Ruminantes e Equídeos. Vol.1. $3^{\text {rd }}$ ed. Pallotti, Santa Maria.

Germano P.M.L., Miguel O., Chamelet E.L.B. \& Morita L.T.M.S. 1977. Estudo comparativo entre as técnicas de coloração de Sellers, imunofluorescência direta e inoculação em camundongos, aplicadas ao diagnóstico laboratorial da raiva canina. Revta Fac. Med. Vet. USP 14:133-141.

Haines D.M. \& West K.H. 2005. Immunohistochemistry: Forging the links between immunology and pathology. Vet. Immunol. Immunopathol. 108:151-156.

Hamir A.N., Moser G. \& Rupprecht C.E. 1992. Morphologic and immunoperoxidase study of neurologic lesions in naturally acquired rabies of raccoons. J. Vet. Diagn. Invest. 4:369-373.

Hamir A.N., Mose G., Wampler T., Hattel A., Dietzschold B. \& Rupprecht. 1996. Use of a single anti-nucleocapsid monoclonal antibody to detect rabies antigen in formalin-fixed, paraffin-embedded tissues. Vet. Rec. 138:114-115.

Herzog E. 1965. Histologic diagnosis of rabies. Arch. Pathol. 39:279280.

Jackson A.C. \& Reimer D.L. 1989. Pathogenesis of experimental rabies in mice: An immunohistochemical study. Acta Neuropathol. 78:159-165.

Jogai S., Radotra B.D. \& Banerjee A.K. 2000. Immunohistochemical study of human rabies. Neuropathology 20:197-203.

Jubb K.V.F. \& Huxtable C.R. 1993. The nervous system, p.267-437. In: Jubb K.V.F., Kennedy P.C. \& Palmer N. (Eds), Pathology of Domestic Animals. Vol.1. $4^{\text {th }}$ ed. Academic Press, San Diego.

Langohr I.M., Irigoyen L.F., Lemos R.A.A. \& Barros C.S.L. 2003. Aspectos epidemiológicos, clínicos e distribuição das lesões histológicas no encéfalo de bovinos com raiva. Ciência Rural 33:25-131.

Lima E.F., Riet-Correa F., Castro R.S., Gomes A.A.B. \& Lima F.S. 2005. Sinais clínicos, distribuição das lesões no sistema nervoso e epidemiologia da raiva em herbívoros na região Nordeste do Brasil. Pesq. Vet. Bras. 25:250-264.

López J.W., Trimarchi C.V., Wandeler A.I. \& Gessel Y.V. 1998/2001. Immunohistochemical recognition of a wide spectrum of Lyssaviruses in formalin-fixed tissues by one monoclonal antibody. Boln Centr. Panam. Fiebre Aftosa 64-67:18-25.

Martínez-Burnes J., López A., Medellín J., Haines D., Loza E. \& Martínez M. 1997. An outbreak of vampire bat-transmitted rabies in cattle in northeastern Mexico. Can. Vet. J. 38:175-177.

Pedroso P.M.O., Pescador C.A., Bandarra P.M., Raymundo D.L., Borba M.R., Wouters F., Bezerra Júnior P.S. \& Driemeier D. 2008. Padronização da técnica de imuno-histoquímica para raiva em amostras de sistema nervoso central de bovinos fixados em formol e emblocados em parafina. Pesq. Vet. Bras. 28:627-632.

Peixoto Z.M.P., Cunha E.M.S., Sacramento D.R.V., Souza M.C.A.M., Silva L.H.Q., Germano P.L., Kroeff S.S. \& Kotait I. 2000. Rabies laboratory diagnosis: Peculiar features of samples from equine origin. Braz. J. Microbiol. 31:72-75.

Perl D.P. \& Good P.F. 1991. The pathology of rabies in the central nervous system, p.164-188. In: Baer G.M. (Ed.), The Natural History of Rabies. $2^{\text {nd }}$ ed. Boca Raton, Boston. 
Radostits O.M., Gay C.C. \& Hinchcliff K.W. 2002. Clínica Veterinária. 9a ed. Guanabara Koogan, Rio de Janeiro, p.1077-1083.

Rech R.R., Rissi D.R., Silva M.C., Inkelmann M.A. \& Barros C.S.L. 2006. Histomorfologia do gânglio de Gasser, da rete mirabile carotídea e da hipófise de bovinos: estudo de 199 casos. Pesq. Vet. Bras. 26:105111.

Rech R.R. 2007. Alterações no encéfalo de bovinos submetidos à vigilância das encefalopatias espongiformes transmissíveis. Tese de Doutorado em Medicina Veterinária, Universidade Federal de Santa Maria, Santa Maria, RS. 228p.

Reis M.C., Costa J.N., Peixoto A.P.C., Figueiredo L.J.C., Menezes R.V., Ferreira M.M. \& Sá J.E.U. 2003. Aspectos clínicos e epidemiológicos da raiva bovina apresentados na casuística da clínica de bovinos (Oliveira dos Campinhos, Santo Amaro, Bahia), Universidade Federal da Bahia, durante o período de janeiro de 1990 a dezembro de 1999 (relato de caso). Revta Bras. Saúde Prod. Anim. 4:12-17.

Riet-Correa F., Riet-Correa G. \& Schild A.L. 2002. Importância do exame clínico para o diagnóstico das enfermidades do sistema nervoso em ruminantes e eqüídeos. Pesq. Vet. Bras. 22:161-168.

Rodriguez L.L., Roehe P.M., Batista H. \& Kurath G. 2007. Rhabdoviridae, p.691-718. In: Flores E.F. (Ed.), Virologia Veterinária. UFSM, Santa Maria.

Rondon E.S., Bastos P.V., Silva D.A. \& Piccinini R.S. 1995. Estudo comparativo da sintomatologia clínica de bovinos suspeitos de raiva. Revta Bras. Med. Vet. 17:253-256.

Summers B.A., Cummings J.F. \& Lahunta A. 1995. Veterinary Neuropathology. Mosby, Baltimore, p. 95-99.

Sureau P., Ravisse P. \& Rollin P.E. 1991. Rabies diagnosis by animal inoculation, identification of Negri bodies, or Elisa, p.204-214. In: Baer G.M. (Ed.), The Natural History of Rabies. $2^{\text {nd }}$ ed. Boca Raton, Boston.

Swanepoel R. 2004. Rabies, p.1123-1182. In: Coetzer J.A.W. \& Tustin R.C. (Eds), Infections Diseases of Livestock. Vol.2. $2^{\text {nd }}$ ed. Oxford University Press, Cape Town.

Teixeira T.F., Holz C.L., Caixeta S.P.M.B., Dezen D., Cibulski S.P., Silva J.R., Rosa J.C.A., Schmidt E., Ferreira J.C., Batista H.B.C.R., Caldas E., Franco A.C. \& Roehe P.M. 2008. Diagnóstico de raiva no Rio Grande do Sul, Brasil, de 1985 a 2007. Pesq. Vet. Bras. 28:515520.

Vural S.A., Alcigir G. \& Berkin S. 2001. Immunohistochemical and histopathological studies of fixed rabies virus in goats. Onderstepoort $\mathrm{J}$. Vet. Res. 68:83-89.

Woldehiwet Z. 2005. Clinical laboratory advances in the detection of rabies virus. Clin. Chim. Acta. 351:49-63.

Zimmer K., Wiegand D., Manz D., Frost J.W., Reinacher M. \& Frese K. 1990. Evaluation of five different methods for routine diagnosis of rabies. J. Vet. Med. B 37:392-400. 